\title{
NÓS DAS REDES
}

\author{
Maria Cristina Silva Costa*
}

\section{FAMÍLIAS DE MIGRANTES}

Em pesquisa com um grupo de quarenta e seis trabalhadores rurais temporários de Ribeirão Preto (SP), em sua maioria excamponeses e migrantes recentes do campo para a cidade, constatei o que estudos anteriores já revelavam: o destacado papel desempenhado pelo parentesco, na migração de pessoas de origem rural e em suas tentativas de integração no contexto urbano.

A família, de grande importância na estruturação do universo tradicional camponês, mantém-se como um valor que permanece e se renova na cidade. Mas, a organização interna dela e a maneira como é concebida revelam adequação às condições urbano-industriais, justapondo-se atributos de duas ordens culturais diversas: tradicional e moderna. Esta mescla expressa, sem dúvida, a transição social e cultural vivida no deslocamento do universo rural ao urbano e na transformação de camponeses (colonos, pequenos sitiantes, meeiros, etc.) em trabalhadores rurais proletarizados.

De maneira geral, para o grupo pesquisado - assim como para outros segmentos das classes populares (Durham, 1973 e 1980; Macedo, 1979) - embora a família, na cidade, não se configure como unidade de produção econômica, fundamento de sua relativa autonomia no mundo rural, permanece núcleo de grande importância, que até se fortalece no mundo urbano. Isto porque ela garante, por um lado, como unidade de rendimentos, a solução conjunta das questões de sobrevivência. Por outro lado, enquanto unidade de consumo, torna-se o centro para a definição coletiva de projetos de vida e de estratégias visando assegurar determinado nível de consumo de bens.

Acresce a estes aspectos, o fato de que as redes de parentes e amigos estabelecidas nas localidades de origem atuam como pré- requisitos, entre migrantes, para a fixação na cidade, facilitando a busca de moradia e de ocupações para os que chegam, com base em compromissos morais sedimentados pela proximidade dos laços afetivos.

E mais, para os migrantes, a vida na cidade acaba por resultar em intensificação dos laços de parentesco, não apenas pelo potencial de mobilização dessas relações para enfrentar as múltiplas carências de um grupo egresso do mundo rural, como também pela segurança emocional que a convivência familiar proporciona, perante o mundo urbano desejado, mas que segrega, isola e hostiliza aqueles que não são portadores dos saberes, condutas e habilidades por ele requisitados.

$\mathrm{Na}$ transição experimentada por migrantes pobres, as redes de relações pessoais e a família, muito importantes no universo holista camponês - estruturado eticamente sobre valores como hierarquia e honra no convívio familiar, reciprocidade nas trocas, liberdade e autonomia no trabalho - são acionadas, porém não como um apego irracional a padrões do passado (Costa, 1993; Sarti, 1994).

\section{A ORGANIZAÇÃO DA VIDA FAMILIAR}

Muito significativa, no que diz respeito à importância do parentesco e aos ajustes empreendidos na transição para o mundo urbano, é a experiência de cinco sujeitos da pesquisa, todos aparentados e provenientes de áreas rurais próximas, no Paraná, que habitam uma granja desativada, na periferia de Ribeirão Preto.

Inicialmente, deslocaram-se para a cidade um tio (José) e seu sobrinho (Antônio)., para trabalharem no corte de cana durante duas safras consecutivas. Ficaram sabendo por "um colega de bar" da existência da granja, onde o tio conseguiu em- prego de vigia e moradia para os dois. No ano seguinte, a família de Antônio (pais e oito irmãos) mudou-se para a granja. Posteriormente, um irmão de José e do pai de Antônio transferiu-se para o mesmo local, com sua mulher e filho. Após três anos, chegou outro irmão, que se separara da esposa no Paraná.

Quando as contatei, dezesseis pessoas unidas em uma grande família habitavam os cômodos (alugados) da granja. Neste caso, o grupo familiar concentrou-se em redor dos dois membros da família que primeiro migraram e facilitaram a migração dos demais, encaminhando a solução das questões relativas aos primeiros ajustamentos à vida urbana.

Contudo, ao organizar-se como rede de parentesco consangüíneo e afim em torno do mesmo espaço de moradia representado pela granja, o grupo acabou constituindo uma "família extensa", na qual a ajuda mútua é acionada sempre que necessária e a partilha dos parcos recursos do local se faz segundo regras de convivência bem definidas.

Mas, não foram apenas estes os que ampliaram seus laços familiares: ao todo, vinte e seis, dos quarenta e seis sujeitos pesquisados, constituíram "famílias extensas". Também no popular "João de Barro" (Bairro Alto), que concentra grande número dos "bóias-frias" de Guariba, muitas famílias articulavam-se como "famílias extensas", no início da década de noventa, quando as pesquisei.

Como "família extensa" refiro-me a dois tipos distintos de teias de parentes reunidos em um mesmo espaço de convívio doméstico e compartilhando recursos. As famílias extensas do primeiro tipo são compostas por duas gerações, cujos vínculos se estabelecem sobre o parentesco traçado em linha colateral (tios, sobrinhos. primos, isto é, grupos de irmãos, suas esposas ou esposos e filhos); o segundo tipo 
é formado por três gerações, com parentesco traçado em linha direta (avô, pai/mãe. filho, isto é, um casal mais velho, seus fiIhos, genros e noras, netos).

Tais agrupamentos familiares aproximam-se das "famílias compostas" definidas por Lia Fukui como famílias "formadas por vários grupos familiares reunidos em um único grupo doméstico e unidos por parentesco ou aliança" (1979, p. 131). As "famílias compostas" que, segundo a autora, tendem ao tipo família extensa são encontradas, todavia, em caráter minoritário nos bairros rurais de sitiantes tradicionais.

Mello e Souza (1987), por sua vez, descreve "blocos familiares" rurais existentes no passado em comunidades "caipiras" e constituídos através da justaposição de parentes prolongando a família nuclear, sem configurar, porém, uma unidade doméstica. As mudanças provocadas pela exposição à influência urbana e pelo avanço do capitalismo no campo, ao acarretarem o enfraquecimento da estrutura dos grupos de vizinhança nos bairros rurais, promoveram, de acordo com o autor, o fortalecimento desses "blocos familiares" camponeses como estratégia grupal de resistência à pauperização. Os blocos familiares assim redefinidos correspondem a grupos de solidariedade perpassada pelo parentesco, que compensam a debilitação dos laços de vizinhança entre os não-parentes.

As "familias extensas" do primeiro tipo analisado entre os trabalhadores rurais migrantes fixados em Ribeirão Preto (agrupamentos por justaposição de irmãos e respectivas famílias) assemelham-se aos blocos familiares descritos por Mello e Souza, compostos por várias famílias elementares ou conjugais, mais indivíduos isolados, comportando-se, sob determinados aspectos, como um grande grupo doméstico. Diferenciam-se dos blocos familiares formados nos bairros rurais exatamente porque estabelecem, na cidade, uma unidade residencial coesa, ainda que a maior parte das famílias conjugais disponha de acomodações isoladas no interior de espaços habitados coletivamente (na granja mencionada e em cortiços).

O segundo tipo de família que designo como "extensa" - unidades conjugais vin- culadas pelo parentesco em linha direta vive reunido em um grupo doméstico de convívio íntimo, sob um mesmo teto ou num conjunto de moradias localizadas em um único terreno (habitantes de favelas). Diferentemente das famílias extensas do primeiro tipo, na maioria dos agrupamentos familiares de três gerações existe uma cozinha única, com a convergência parcial de rendimentos das famílias conjugais e o preparo de alimentos a cargo de uma das mulheres do grupo.

Mesmo não configurando unidades de produção - a não ser no sentido restrito da produção de valores de uso -, as redes de parentes organizadas como famílias extensas dos dois tipos encontrados comportamse como unidades de consumo e de rendimentos, em grau maior ou menor, de solidariedade e ajuda mútua.

No entanto, as informações dos que assim vivem deixam muito claro ser esta forma de aglutinação familiar contraditória com o padrão ideal predominante entre eles, que é o da família conjugal completa (marido, mulher e filhos). É possível depreender, pois, que a ampliação dos grupos familiares, distante da conformação desejada pelos sujeitos, faz parte das estratégias de sobrevivência no contexto urbano. Para eles, a família ampliada representa maior vigor para a adaptação às exigências e aos estímulos da vida na cidade, bem como resistência à pobreza e ao descenso da condição relativamente autônoma de camponeses para a de trabalhadores rurais subalternos e temporários.

De maneira correlata, cabe notar que as famílias extensas encontradas entre esses migrantes rurais não correspondem à persistência de valores ou padrões de organização tradicionais da família camponesa. Ainda que a família extensa patriarcal tenha sido a forma predominante nas classes senhoriais, não se pode reconhecêla como característica da cultura cabloca, nem da organização familiar nas camadas pobres da sociedade rural, à exceção de áreas de colonização estrangeira. De acordo com Durham (1973, p. 62), o nomadismo decorrente da "instabilidade do modo de apropriação da terra" e a ausência de mercados e de incentivos para o aumento da produtividade estariam na base do predomínio da família conjugal entre os camponeses brasileiros.

Mello e Souza (1987), que indica uma aproximação da "família caipira" de parceiros paulistas com as relações familiares, valores, formas de sociabilidade e padrões patriarcais, apresenta, entretanto, como unidade fundamental de agrupamento tradicional do caipira, não a família extensa, mas o "bairro" rural. Este se estrutura sobre relações vicinais e envolve sociabilidade e solidariedade duradouras de grupos familiares elementares interdependentes, não necessariamente aparentados. É apenas num contexto de crise da sociedade tradicional que tais relações deixam de operar ou enfraquecem muito, ficando as formas de solidariedade e de cooperação restritas ao circuito do parentesco dentro do bairro ou entre bairros.

Embora o autor destaque a permanência, no passado, de filhos casados na residência paterna (entre pequenos proprietários e posseiros), prolongando a sujeição filial, nota que a tendência à mobilidade, associada à precariedade da posse da terra e à agricultura itinerante atua "no sentido de fechar sobre si mesma a família nucle$a r$ " (op. cit., p. 253). Com relação aos blocos familiares, antes um prolongamento das famílias nucleares e depois, com o enfraquecimento da estrutura do grupo de vizinhança, transformados em unidade fundamental de estruturação da solidariedade, o autor ressalta que eles não se confundem com a família extensa. Constituem, isto sim, blocos de solidariedade interfamiliar, fundamental quando os parceiros das trocas restam limitados a indivíduos e famílias elementares relacionados entre si pelo parentesco.

De maneira geral, a literatura sobre a família camponesa brasileira demonstra a precedência do padrão conjugal entre os lavradores pobres, ao contrário da forma tradicional de organização familiar da aristocracia rural. De estrutura complexa e comportando pelo menos três gerações, que compõem uma unidade de produção e de reprodução em sentido amplo, a família extensa aparece como característica de comunidades camponesas em outros países, mas não no Brasil, onde a segmentação dos grupos domésticos em famílias nucleares estabeleceu-se como padrão. 
Visto por este ângulo, não seria pertinente, portanto, afirmar que a construção de famílias extensas por migrantes rurais na cidade corresponde à persistência de formas de organização familiar tradicionais características da sociedade rural brasileira.

\section{A FORMAÇÃO DAS REDES}

Pelo ângulo das histórias de vida dos sujeitos pesquisados, verifica-se que existem apenas referências isoladas ao convívio temporário ou permanente em famílias extensas, no meio rural. São poucos os relatos de união de famílias elementares vinculadas pelo parentesco em situações de meação e de arrendamento, vivendo e produzindo em conjunto nas terras de trabalho e morada.

Os relatos da vida anterior, "na roça", revelam o predomínio da dispersão dos grupos familiares elementares, agora unificados na cidade. Entre os trabalhadores rurais migrados do Paraná, por exemplo, a convergência recente articulada na granja da periferia de Ribeirão Preto inova a configuração familiar: as teias de parentes tecidas na cidade reúnem grupos domésticos que antes viviam dispersos em fazendas diversas.

Com a mudança do campo para a cidade, transformaram-se, de colonos e meeiros, em assalariados/diaristas; de produtores que garantiam a subsistência com relativa autonomia, em carpidores de cana, dependentes do salário e do comércio urbano, para a aquisição dos alimentos. Os grupos domésticos restritos aglutinaramse, dando origem à família ampliada e assim tornada apta a enfrentar os desafios da cidade e as condições de seu ingresso nela.

No espaço "urbano" da granja, como também na favela e em outras áreas, esses egressos do mundo rural constroem a comunidade possível sobre redes de sociabilidade que unem parentes na família extensa, podendo incluir amigos e vizinhos. $\mathrm{Na}$ vivência de tipo comunitário assim erigida, a cooperação, a ajuda mútua e normas internas de convívio e controle social diferenciam os "de dentro" e os "de fora", com as marcas de pertencimento assentadas nas relações íntimas e pessoais.

Os filhos que se casam constroem no- vos barracos na favela, junto ao dos pais, ante a impossibilidade de conseguirem ocupar outros terrenos e a inexistência de alternativas para solucionarem o problema habitacional. É comum, aliás, que fiIhos adultos ainda solteiros construam um cômodo isolado dos outros, para servir de dormitório, o que, aparentemente, já representa uma preparação do status de casado.

Na construção, consertos e ampliação das casas e dos barracos, todos cooperam, até crianças e vizinhos, sob a liderança do principal interessado. Nesses momentos, as redes se ampliam com a inclusão de amigos e vizinhos, parceiros do trabalho nos canaviais e da luta paciente pela sobrevivência, indicando a extensão, para outras esferas, dos laços estabelecidos nas atividades produtivas e denotando identidades estabelecidas por interesses comuns.

Predominando sobre as redes organizadas e imbricando-se nelas, acentua-se o parentesco como o vínculo mais importante. Não só a família como instituição social fundamental tem a sua importância reafirmada na cidade, mas o próprio ajustamento ao mundo urbano impõe novas exigências aos grupos familiares, provocando modificações, que redundam até mesmo no surpreendente alargamento verificado.

A junção das unidades familiares permite articular os recursos, de maneira a assegurar a reprodução física e social, face à segregação imposta pelas condições em que se dá sua inserção na vida da cidade. Diante da instabilidade característica da ocupação de trabalhador rural temporário, a ampliação da família e a multiplicação das atividades produtivas de seus membros asseguram a sobrevivência de todos, nos momentos cíclicos de redução do ganho e de desemprego.

As dificuldades de obtenção de moradia podem ser contornadas, se o agrupamento familiar se mantiver unido: edificase mais um cômodo ou dependência junto à casa, mais um barraco no terreno, ou, ainda, recursos provenientes da remuneração de vários componentes da família engajados no processo produtivo são capitalizados para a aquisição de casa ou terreno.

Ante a carência de creches e de outras instituições que possam atender aos neces- sários cuidados das crianças pequenas, a família ampliada também representa uma garantia para os seus membros. Remunerado ou não, este trabalho costuma ser desenvolvido por parentes não inseridos no mercado formal de trabalho.

Unidos em redes de cooperação e solidariedade, que perpassam as relações de parentesco e fundem várias unidades conjugais em uma família extensa, esses migrantes recentes extraem de sua bagagem cultural os laços significativos que lhes asseguram, em novo arranjo, formar o "nós" fortalecido sohre n qual assentam as bases da nova vida. De modo semelhante aos blocos familiares analisados por Antônio Cândido, a convergência dos grupos familiares permite melhor enfrentar as carências e a situação de crise experimentadas em seu ingresso na ordem da modernidade, passando a rede familiar a atuar na cidade como "cápsula protetora" de seus membros, à maneira da comunidade rural em relação ao campesinato (Mendras, 1978).

* Maria Cristina Silva Costa é Doutora em Antropologia Social e docente da Escola de Enfermagem de Ribeirão Preto, USP.

\section{REFERÊNCIAS BIBLIOGRÁFICAS}

COSTA, M. Cristina S.

(1993) Vidas em Tránsito: trabalhadores rurais temporários na periferia de Ribeirăo Preto. Dissertaçāo de Mestrado, Departamento de Antropologia, FFLCH/USP.

DURHAM, Eunice R.

(1973) A Caminho da Cidade. São Paulo Perspectiva.

DURHAM, Eunice R.

(1980) "A Familia Operária: consciência e ideologia". In: Dados, vol. 23, n², pp. 201-212, Rio de Janeiro, Campus.

FUKUI, Lia F. G.

(1979) Sertão e Bairro Rural (Parentesco e Familia entre Sitiantes Tradicionais). Sâo Paulo, Ática

MACEDO, Carmen C.

(1979) A Reprodução da Desigualdade. São Paulo, Hucitec.

MELLO E SOUZA, Antônio C.

(1987) Os Parceiros do Rio Bonito. São Paulo, Duas Cidades.

MENDRAS, Henri

(1978) Sociedades Camponesas. Rio de Janeiro, Zahar.

SARTI, Cynthia A.

(1994) A Familia como Espelho: um estudo sobre a moral dos pobres na periferia de São Paulo. Tese de Doutoramento, Departamento de Antropologia FFLCH/USP. 